\title{
Perspectivas de cambio desde el Sur. Pensamiento crítico desde la raíz*
}

Perspectives of change from the south. Critical thinking from the root

Perspectivas de mudança desde o sul. Pensamento crítico desde a raiz

Fecha de entrega: 12 de diciembre de 2015

Fecha de evaluación: 5 de junio de 2016

Fecha de aprobación: 30 de junio de 2016

Mariagiulia Costanzo ${ }^{* *}$

\section{Resumen}

Esta contribución se centra sobre la crítica al pensamiento dominante, que toma forma en el paradigma neoliberal, artífice de desigualdades sociales, pobreza estructural y daños ambientales. Una expresión alternativa a este modelo son los movimientos sociales latinoamericanos, que toman fuerza y hacen propuestas desde abajo, desde los "márgenes" de la sociedad, representando el motor de un proceso de cambio y proponiendo un paradigma incluyente y capaz de envolver elementos como la justicia social y el acceso libre a la tierra, entre muchos otros.

* Este escrito es parte del recorrido investigativo de la autora en relación al tema de medio ambiente y ecologia bajo una perspectiva crítica y social, por medio de la cual se analizan las repercusiones e implicaciones del territorio y el entorno natural en la cultura y la organización social. DOI: http://dx.doi.org/10.15332/s0120-8462.2016.0115.02

* Ph.D., Universidad Pablo de Olavide, Sevilla. Doctorado en Medio Ambiente y Sociedad. Correo electrónico:mg8.costalarico@gmail.com 
En este sentido, el Buen Vivir representa el principio inspirador de los movimientos indígenas que proponen un proyecto alternativo que se opone al paradigma dominante y se presenta como respetuoso de las diversidades.

Palabras clave: buenos vivires, movimientos indígenas, márgenes, memoria biocultural.

\section{Abstract}

This contribution focuses on the criticism to dominant thinking, which takes shape in the neoliberal paradigm, the creator of social inequalities, structural poverty and environmental damages. An alternative expression to this model are the Latin American social movements, which take strength and make proposals from below, from the "margins" of society, representing the engine of a process of change and proposing an inclusive paradigm and capable of involving elements such as social justice and free access to land, among many others. In this sense, Good Living represents the inspiring principle of the indigenous movements that propose an alternative project that opposes the dominant paradigm and presents itself as respectful of diversity

keywords: Good Living, indigenous movements, margins, biocultural memory 


\section{Resumo}

Esta contribuição foca-se na crítica ao pensamento dominante, que se forma no paradigma neoliberal, artífice de desigualdades sociais, pobreza estrutural e danos ambientais. Uma expressão alternativa a esse modelo são os movimentos sociais latino-americanos, que ganham forca e fazem propostas desde abaixo, desde as "margens" da sociedade, representando o motor de um processo de mudança e propondo um paradigma inclusivo e capaz de envolver elementos como a justiça social e o acesso livre a terra, entre muitos outros. Neste sentido, o Bom Viver representa o princípio inspirador dos movimentos indígenas que propõem um projeto alternativo que se opõe ao paradigma dominante e se apresenta como respeitoso das diversidades.

Palavras-chave: Bons Viveres, movimentos indígenas, margens, memória biocultural.

\section{Introducción}

1999 ha marcado no solamente el fin simbólico de un milenio, sino el principio de un ciclo de luchas globales alrededor de temas y problemáticas generadas por la globalización, empezado en Seattle con la manifestación contra la Cumbre de la OMC (Hard y Negri, 2004). Las manifestaciones de Seattle han dado vida, a su vez, a una serie de protestas realizadas en los años siguientes, ya en América del Norte y Europa, como en el sur del mundo, revelando la protesta contra el Fondo Monetario Internacional (FMI), el Banco Mundial (BM) y el NAFTA (North American Free Trade Agreement), es decir formas de resistencia a las privatizaciones impuestas por la ideología de la globalización económica (Hard y Negri, 2004). Así, mientras las multinacionales conciben el mundo en términos de propiedad privada, los movimientos quieren defender los recursos locales (y globales) en cuanto a bienes comunes, defendiendo las propias diversidades biológicas y culturales (Shiva, 2006).

El desarrollo sin frenos ha provocado, por un lado, un crecimiento exponencial en la explotación de los recursos, y por otro, un consumismo sin frenos (sobre todo en los países del norte del mundo), tanto que hemos llegado a un punto de no retorno por el 
agotamiento de los recursos y la producción de residuos contaminantes. Los mismos estudiosos occidentales declaran, a través de indicadores científicos medioambientales, que si no se va a cambiar el estilo de desarrollo, la supervivencia del planeta y de la humanidad estará pronto en gravísimo peligro. Muchas soluciones que se han producido han sido el resultado de la generación, a menudo, de mecanismos de mercados que trataban de limitar las emisiones, pero que no solo no las han limitado, sino que han justificado constantemente las acciones de las empresas que han comprado la licencia "verde", siguiendo con la contaminación (De la Cuadra, 2015). Por esta razón, el Buen Vivir, que pone fuertemente en cuestión el modelo productivista, representa el principio inspirador de muchos movimientos sociales, también los movimientos que no son latinoamericanos, ni indígenas: a partir de la experiencia en Latinoamérica, una red de actores transnacionales está tratando de articular un proyecto alternativo que intenta oponerse al paradigma dominante (Vanhulst, 2015) y a presentarse como respetuoso ante las diversidades y por la sustentabilidad.

El Buen Vivir es un proyecto en construcción (como veremos), se presenta más como una plataforma que como un concepto único y preciso (Loera, 2015). La diversidad de ideas y discursos asociados al Buen Vivir hacen que se preste perfectamente a la lucha por la justicia social que está teniendo lugar en muchas partes del mundo (Loera, 2015), porque el Buen Vivir implica asumir una alternativa al paradigma de la euromodernidad, moviéndose en un espacio entre márgenes donde coexisten saberes que se articulan entre diferencias ontológicas, o lo que es lo mismo, los márgenes como lugar de lucha entre diferentes proyectos políticos y distintas realidades (Loera, 2015).

El paradigma actual mira al mundo con una concepción dual en la cual existen "dos mundos", uno supuestamente "atrasado", donde se encuentran campesinos e indígenas, que impiden el crecimiento, y el otro en donde residen el conocimiento y la modernidad, que sin ser discutidos ni discutibles, solucionan a su manera perfecta cualquier problema (Carvalho y Friggeri, 2015). Esta concepción (Modernidad/ Colonialidad) colonial del mundo, hace que se mantenga un control en cuatro niveles (Mignolo, 2008):

- Economía (apropiación de tierra, recursos, explotación, creación de organismo multilaterales, por ejemplo FMI);

- autoridad (derecho y relaciones internacionales, formas de gobierno); 
- género;

- conocimiento.

En primer lugar todo lo que no es hombre, blanco y cristiano, o sea quien maneja y controla el saber (Loera, 2015), no tiene autoridad. En segundo lugar, creando la asociación por la cual el hombre es el racional y la mujer la emotiva, se justifica un control de género, conforme a una presunta "naturaleza" humana (Momsen, 2004). En tercer lugar, el modelo neoliberal cosifica y mercantiliza cualquier elemento que pueda traer beneficios económicos, así que todo se reduce a un producto industrial. Nunca como ahora esto es más verdadero: vivimos en la época en la que se producen más alimentos en la historia de la humanidad, y una persona de cada diez en el mundo sufre de hambre, mientras 800 millones de personas son obesas (Patel, 2011), dos síntomas del mismo problema, es decir un sistema de poder que controla hasta cuándo, cómo y dónde alimentarse y a quién alimentar.

El patriarcado, de estas formas, regula cada aspecto de la vida. Es esta la razón por la cual es necesario un empoderamiento por parte de los grupos considerados "débiles". Por tanto, imaginar un cambio de paradigma significa derrocar los instrumentos universales de clasificación social y de dominación como los de raza, clase y género. Además, en esta contribución se evidencia la centralidad de América Latina en la recuperación de la memoria y de las identidades humanas.

Si Juan José Bautista Segalés (2014) ya subrayó la necesidad de deconstruir el pensamiento crítico de la realidad científica a partir de su raíz, históricamente basada en el pensamiento griego antes y europeo después (según una supuesta mirada eurocentrada), afirmando que: "la realidad que aparecía ante nosotros como problema ya no era la europeo-occidental, sino la latinoamericana, y específicamente los problemas que planteaba al pensar el mundo andino amazónico" (Bautista, 2014, p. 10), este artículo pretende demostrar que dicha raíz andina es algo que todo el mundo debe explorar, en cuanto a que la historia del ser humano ha cambiado desde un dramático hecho que pertenece a la entera humanidad: el genocidio de los nativos de Abya Yala.

En este trabajo se verá en el primer capítulo la construcción y las características de la mirada dominante occidental, en el segundo capítulo se empezará la deconstrucción del modelo patriarcal, partiendo del concepto de raza y analizando la búsqueda de la propia identidad mediante la recuperación de la memoria biocultural. Finalmente, se 
analizará la propuesta política del horizonte de los Buenos Vivires desde los movimientos indígenas, tratando de demostrar que la raíz del pensamiento crítico reside en una perspectiva que viene desde el sur global.

\section{La mirada occidental}

La primera vez que me acerqué a la Antropología lo hice con Antropologia in sette parole chiave de Vincenzo Matera (2006), un manual para aprender las bases de la disciplina mediante siete palabras claves. La palabra que capturó mi atención fue incompletitud: ¿qué podía querer indicar esta palabra, si siempre me han explicado que el ser humano es el más completo entre los seres vivos? Así descubrí que sí hay una corriente de pensamiento que sostiene que el ser humano es el animal más fuerte e inteligente, idea iluminista que enseñan desde el colegio, sin embargo hay otra corriente de paleontología que afirma justo lo contrario, es decir que el ser humano es un animal defectuoso desde el punto de vista estrictamente biológico, menos dotado en cuanto a fuerza e instintos (Matera, 2006).

El ser humano funde dos componentes, uno orgánico, hereditario como en las especies animales y vegetales, el otro cultural, o sea ambiental en el sentido que se transmite socialmente a través de la palabra, la tradición y el aprendizaje. Lo que es interesante es que mientras otros animales (también entre los primates que son los animales parecidos a los homínidos), tienen comportamientos naturales, innatos, con un principio de dominación jerárquica y uno de imitación para el aprendizaje, el ser un humano necesita un sistema de reglas codificadas que establecen modos de accionar no innatos que se puedan dictar y que constituyen una cultura. La cultura representa un principio que reproduce una complejidad social muy alta y responde a la exigencia de instruir a los individuos (mediante aprendizaje), para que se reproduzcan siempre las mismas dinámicas sociales. La cultura, por lo tanto, es un elemento indispensable, no solamente para adquirir una ventaja que no se posee naturalmente, sino una integración vital a la supervivencia biológica (Matera, 2006).

El antropólogo Eibl-Eibesfeldt (1993) explica que incluso el ser humano está "constreñido" a la experiencia cultural: mientras los genes de los animales les confieren las informaciones necesarias para sobrevivir (comer, defenderse de los depredadores, nadar, caminar, correr), los de los seres humanos no están "programados". Resulta, por tanto, que el ser humano es tan "incompleto", débil e incapaz originariamente de remediar 
a su incompletud con la cultura, donde por cultura se entiende como la producción de significado, es decir, dar un sentido a todo lo que ocurre. El Homo Sapiens es un productor de sentido y el mundo donde vivimos no es neutro, sino un mundo hecho por objetos que asumen sentido en relación a la experiencia (Matera, 2006).

Parece claro que hablar de naturaleza humana como única y válida por todo el mundo es un espejismo. Cultura es acción/transformación de la naturaleza y otorgamiento de sentido, no solamente no es correcto hablar de "la naturaleza humana", no deberíamos hablar ni siquiera en términos de cultura, sino de culturas, porque cultura son las diferentes culturas, diferentes idiomas, diferentes memorias.

Infortunadamente ya sabemos que la narración de la historia humana no comprende esta visión de la convivencia de las diversidades, y que al contrario existe un pensamiento dominante que empuja la homologación a él. Veremos en qué medida.

\subsection{El problema del "otro"}

Respecto a la cultura, la tendencia conocida es aquella de atribuirle aspectos de naturaleza, tal y como si fuera "natural" un comportamiento o una actitud y sobre todo como si existiera una cultura más verdadera que otra.

Definir a los "otros" y a las otras culturas puede ocurrir de manera inclusiva o exclusiva: se puede percibir el otro como algo al cual se pertenece, como parte de un nosotros con valores e identidad en común, o como una abstracción, es decir algo fuera de mí y lejos de mí (Todorov, 1992).

Hay muchos ejemplos históricos que narran cómo los seres humanos se han relacionado entre ellos a pesar de sus diferencias, sin embargo el más emblemático es el encuentro con los nativos de Abya Yala por parte de los españoles. Por cierto, no era la primera vez que los europeos encontraban otros continentes, pero hay un elemento de unicidad en el contacto con el Nuevo Mundo, en cuanto a que se cumplió el más grande genocidio en la historia de la humanidad. A pesar de que la historia humana siempre ha visto conquistas y derrotas, descubrimiento del otro y colonizaciones, es propio la conquista de América que anuncia el nacimiento de la sociedad moderna, y funda la actual identidad del paradigma dominante que tiene como inicio la fecha 
simbólica de 1492, el año durante el cual Colón cruza el océano Atlántico. Desde entonces Colón marca las características de los conquistadores: evangelización y colonización, que se basan en las actitudes que el mismo Colón tuvo, es decir la negación de la diversidad de los nativos y la asimilación de ellos a la naturaleza en cuanto a gente "salvaje" (Todorov, 1992).

El juicio de Colón hacia los nativos se basa en la percepción que él tiene, distingue dos componentes que encontramos hasta nuestros días en la relación colonizador/ colonizado: desde un lado piensa a los nativos como seres humanos completos y con los mismos derechos que él tiene, pero esta actitud conduce al asimilacionismo y, por tanto, a la proyección de sus mismos valores sobre los otros. Desde otro lado les ve con la mirada de la diferencia, en términos de superioridad, y negando así la existencia de una sustancia humana "realmente otra" que no sea inferior o imperfecta. Estos dos niveles de alteridad se construyen mediante el egocentrismo y la identificación de sus propios valores con los valores en general, y del yo con el universo, como si el mundo fuera uno (Todorov, 1992).

Al mirarlo bien, este comportamiento es la base de lo que Sousa Santos llama "pensamiento abismal" (2009, p. 23), que se manifiesta en el conocimiento y en el derecho moderno construidos por subsistemas visibles e invisibles de manera que las distinciones invisibles sean el fundamento de las visibles. Esto se traduce, en el campo del conocimiento, por ejemplo en la concesión del monopolio del juicio entre lo verdadero y lo falso a la ciencia moderna. Esta supuesta universalidad en realidad es relativa, visto que se puede demostrar solo en determinados casos, con determinadas condiciones; a pesar de ello, ha servido para aplastar los conocimientos populares, campesinos e indígenas, declarándolos irrelevantes y no fiables.

"El pensamiento moderno occidental avanza operando sobre líneas abismales que dividen lo humano de lo subhumano de tal modo que los principios humanos no quedan comprometidos por prácticas inhumanas. Las colonias proveyeron un modelo de exclusión radical que prevalece hoy en día en el pensamiento y la práctica occidentales modernos como lo hicieron durante el ciclo colonial. Hoy como entonces, la creación y la negación del otro lado de la línea son constitutivas de los principios y prácticas hegemónicas (Sousa Santos, 2009)". 
El pensamiento occidental marginaliza todo lo que no entra en los cánones dictados. Así, a pesar de que los márgenes a él subordinados tienen un territorio más amplio de la supuesta centralidad del occidente, no ejercitan poder (Soler y Pérez, 2014). Analicemos cuáles son los sesgos de la mirada occidental.

\subsection{Lo sesgos de la mirada occidental}

Los elementos que constituyen el eurocentrismo son reconocibles entre algunas de sus características (Quijano, 2000):

a. La articulación entre un dualismo: tradicional/moderno, hombre/mujer, primitivo/civilizado, europeo/no europeo.

b. Un evolucionismo lineal y unidireccional desde el estado de naturaleza a la sociedad moderna (europea).

c. La naturalización de las diferencias culturales y fenotípicas entre grupos y relaciones humanas mediante el uso del concepto de raza.

d. La distorsión de la reubicación temporal de las diferencias, produciendo una percepción por la cual todo lo que no es europeo es pasado.

Todas estas operaciones intelectuales interdependientes están cultivadas y desarrolladas dentro de lo que Aníbal Quijano llama "colonialidad del poder", que construye el pensamiento dominante. Los sesgos de la mirada occidental hacen que la realidad parezca abstracta y unidimensional; estos son tres: etnocentrismo, androcentrismo, antropocentrismo (Soler y Pérez, 2014).

El etnocentrismo. Una de las características de la mirada occidental es la del etnocentrismo, que separa la cultura "civilizada y moderna" de la "atrasada y salvaje" (Santos, 2009).

En la búsqueda de un pensamiento que pueda valorar una mirada que no tenga una huella eurocéntrica, resulta interesante el aporte del estudioso Aníbal Quijano, quien, a partir del concepto de heterogeneidad estructural de José Carlos Mariátegui, elabora las causas y consecuencias del fenómeno de la "pobreza estructural". Esta, de acuerdo con Quijano, es la contracara del capitalismo, que se manifiesta desde la conquista de Abya Yala (Carvalho y Friggeri, 2015). Quijano afirma que el poder 
capitalista (eurocentrado y global) está sujeto por dos ejes: la colonialidad del poder y la modernidad (Lugones, 2008) y que:

\footnotetext{
"La globalización en curso es, en primer término, la culminación de un proceso que comenzó con la constitución de América y la del capitalismo colonial/ moderno y eurocentrado como un nuevo patrón de poder mundial. Uno de los ejes fundamentales de ese patrón de poder es la clasificación social de la población mundial sobre la idea de raza, una construcción mental que expresa la experiencia básica de la dominación colonial y que desde entonces permea las dimensiones más importantes del poder mundial, incluyendo su racionalidad específica, el eurocentrismo" (Quijano, 2000, p. 246).
}

El concepto de raza está construido como instrumento universal de clasificación social de la población del planeta entero y el mecanismo de dominación que consigue por la naturalización de las relaciones económico-sociales, es característico de la modernidad (Carvalho y Friggeri, 2014; Lugones, 2008). El concepto de raza, tal y como se conoce hoy en día, no existía antes de la conquista: se originó para apoyar las relaciones de superioridad e inferioridad basada en referencias fenotípicas entre españoles e indígenas, construyendo una idea en términos de estructuras biológicas diferenciales para justificar la dominación. El concepto de raza produjo nuevas identidades geoculturales, sociales y redefinió otras. Así aparecen nuevas categorías como indios, negros, mestizos; hasta ese entonces ser español o portugués (más tarde europeo) indicaba solo la pertenencia a un país de origen, desde este momento empezó a tener una connotación racial. En términos de relaciones sociales de dominación, significó que estas últimas identidades se asociaron a las jerarquías, al patrón de dominación colonial que se imponía (Quijano, 2000).

Sin embargo, la colonialidad no se refiere solamente a la clasificación racial. Ella controla los ámbitos básicos de la existencia humana, es decir sexo, trabajo, autoridad colectiva, subjetividad/intersubjetividad y producción del conocimiento, creando "un universo específico de relaciones intersubjetivas de dominación bajo una hegemonía eurocentrada" (Quijano citado por Lugones, 2008, pp. 20-22). Se comenzó a entender a Europa como el centro del mundo que colonizó al resto del mundo, en cuanto a que era el único momento más avanzado en un curso lineal de las especies. Asimismo, mitológicamente se difundió la idea de que el mundo estaba dividido entre superior/ inferior, racional/irracional, primitivo/civilizado, tradicional/moderno. 
El androcentrismo. Otro sesgo de la mirada occidental es al androcentrismo, es decir, que las construcciones sociales tienen una centralidad en lo masculino y asignan una posición subordinada a lo femenino (Soler y Pérez, 2014).

En realidad, no existen diferencias de comportamiento congénitas que aparecen en todas las culturas (Ruspini, 2006). Según la antropóloga Margaret Mead (1967), las diferencias de comportamiento se desarrollan mediante el aprendizaje social, por tanto la diferencia sexual es relativa, histórica y sujeta al cambio.

Frente a la supuesta universalidad masculina, se ha excluido a la mujer del ámbito de la subjetividad en cuanto a su definición en negativo, como "lo que no es un hombre" (Ruspini, 2006). En la tradición filosófica occidental, se ha concebido lo femenino como directamente "natural" construyendo un dualismo naturaleza/cultura, paralelos a otros, cuerpo/mente, emoción/razón, masculino/femenino, donde se ha puesto la asociación del hombre a la cultura y se ha conectado la figura de la mujer a la de la naturaleza (Momsen, 2004), sin poner más en discusión la pretendida naturalidad de la mujer, que, al revés, justificó la necesidad de alejar a las mujeres en el ámbito público y del poder político (Ruspini, 2006), otorgándoles el espacio privado del cuidado de los hijos y de la casa. Asimismo, la filosofía occidental ha contrapuesto la esfera personal e íntima a la esfera social y publica, teorizando las diferencias de género en términos de inferioridad femenina respeto a lo masculino.

El paso a la época de la industrialización ha agudizado más este fenómeno, y si bien es verdad que emerge la figura de la obrera, se trata de una mujer joven, no casada, y que consigue solamente tareas menos importantes que las de los hombres. La retórica, en general, es la de que el "hogar natural de una mujer está en casa", mientras que el hombre "trae el pan", y es este el momento en el cual se refuerza la idea romántica de mujer refinada, frágil y económicamente dependiente (Ruspini, 2006). Claramente esta fue la visión de una mirada (blanca) de la clase media-alta.

Randall Collins (1992), explica que en las sociedades "modernas" se asiste a un cambio de posición de la figura de la mujer, difundiendo el pensamiento idealizado de que las mujeres fueran moralmente superiores a los hombres y que, por tanto, se necesitaba usar modos "civiles" con ellas y protegerlas de la grosería masculina (citado por Ruspini, 2006, p. 33). En verdad, este no era más que otro modo para excluirlas de la vida pública. 
Así, culturalmente se construye un femenino doméstico donde se desarrollan actividades de reproducción privada, como la alimentación, la higiene, el vestirse y el descanso, con relaciones basadas en el afecto, y mujeres responsables de un trabajo desvalorizado e invisible, "improductivo", frente a lo público masculino "productivo" (Soler y Pérez, 2014, pp. 29-30).

El patriarcado, de un lado crea una imagen de mujer-marioneta, "femenina" y sensual, maleable y condescendiente, de buen hacer, con un modelo de comportamiento superficial e idealizado, sin embargo no asignado a todas las mujeres, sino a las mujeres de clase media-alta, blancas, que tenían la tarea de hacer hijos blancos, burgueses y que preservaran la cultura dominante (Mead, 1967). Del otro lado, ha dado vida a la explotación silenciosa de las mujeres no burguesas y no blancas, con una división del trabajo entre los sexos totalmente desequilibrada (Hirshman, 1995; Momsen, 2006).

Como los otros sesgos, también el androcentrismo es inadvertido y pasa como algo natural (Soler y Pérez, 2014).

El antropocentrismo. El último sesgo de la mirada occidental es lo que crea el dualismo sociedad/naturaleza, es decir el antropocentrismo: concepto que justifica el ser humano para asignar un valor instrumental a todo lo que no es humano, percibiendo lo seres vivos y la naturaleza en general, como algo que se debe dominar: un recurso a explotar (Soler y Pérez, 2014).

El sistema agroalimentario tal y como lo conocemos hoy, es un perfecto ejemplo de consecuencia de esta visión: reduce todo a producto industrial, a commodity global, e incluso los bienes comunes son tratados como algo de que beneficiarse económicamente (Corrado, 2010; Costanzo 2014).

Desde que el ser humano tiene memoria, la tierra y la alimentación siempre tuvieron un significado especial, al cual se han acercado ritos espirituales y prácticas religiosas propias por su conexión a lo sagrado: tierra y comida se vivían como una donación de los dioses o de Dios (Pérez-Vitoria, 2007). La sacralidad de la comida ha representado un enlace entre lo humano y lo divino, no solamente en la tradición rural sino en todas las creencias y las prácticas ancestrales, y también los rituales religiosos cristianos vienen de estas: abstinencias, ayunos, ofrendas a los espíritus (Costanzo, 2014). Es por esta razón que se entiende por qué la alimentación se convierte en territorio 
de conquista exactamente como la tierra y la mujer: lo que se quiere controlar es la misma vida (Vitale, 2008). El instrumento de la conquista en este caso es la patente.

El origen de la patente es la littera patente (carta patente): esta era un documento oficial con el cual el rey concedía privilegios, títulos, cargos y tierras. El adjetivo patente significa "de público dominio", en cuanto a que las letras que llevaban el sello real se publicaban y eran leídas por toda la población (Shiva, 2002). ¿Y cuándo y dónde aparecen por primera vez las patentes? Aparecen en Europa en el siglo VI, propiamente con el inicio de la época colonial, para conferir territorios conquistados por los monarcas extranjeros conquistados en el nombre de la corona. No es casual que los privilegios concedidos a Colón llevaran el binomio descubrimiento/conquista (Shiva, 2002), en cuanto a que justificaba la colonización y el monopolio sobre las importaciones, y legitimaba la depredación a Abya Yala.

Por lo tanto, en el transcurso de la historia, las patentes se han asociado a la colonización: en principio el objetivo era la apropiación de tierras por parte de los europeos, hoy este objetivo está representado por las economías. La mirada occidental considera las patentes como un derecho "natural", así devienen instrumentos de recolonización: si antes se querían conquistar oro y territorios, ahora se quiere conseguir el control de los mercados y de los sistemas económicos, ¿y cómo se obtiene el control económico?: comprando el "saber" (Shiva, 2002). De acuerdo con Hardt y Negri (2004), la producción de saberes e ideas crea los medios mediante los cuales se forma y se conserva la sociedad, y se construyen las relaciones sociales. Las formas de vida social están construidas por trabajo inmaterial que es biopolítico, en el sentido que no se limita a la esfera económica, sino que es una fuerza social, política y cultural. Aquella biopolítica es una producción de subjetividad y reproducción de nuevas subjetividades en lo social. El biopoder, por tanto, es una forma de poder que regula los tratos biológicos implicados en la producción y reproducción de la vida, que se convierten en estrategia política. De esta forma la misma vida es objeto de poder (Foucault, 1977; Hardt y Negri, 2002).

Las últimas décadas han sido testigo de una depauperización genética trágica implementada por la industria agroalimentaria (Corrado, 2010). El desarrollo de la ingeniería genética y la aplicación de la patente sobre las semillas, a partir de los años ochenta, han provocado verdaderos estragos tecnológicos, un ejemplo es la semilla llamada "terminator", realizada para no reproducirse más de una vez y permitir una sola cosecha, de modo que los campesinos fueran forzados a comprar de nuevo las 
semillas, no pudiendo generarlas autónomamente. La semilla siempre ha sido un recurso compartido, un bien común, por lo que cosificarlo distorsiona la agricultura y roba a los campesinos el primer medio de subsistencia en cuanto a que lo transforma en instrumento tecnológico de pobreza, poniendo en peligro la vida del ser humano y la biodiversidad (Petrini, 2009).

No obstante, en el pasado los estudios sociológicos no se han interesado en el tema de la alimentación, por estar estrictamente conectado al ámbito privado y por tanto a la mujer (Tosi, 2013), y al campo rural "atrasado", es decir a ámbitos secundarios y no relevantes, hoy en día se empieza a entender desde muchos puntos de vista que la comida no es solamente algo que se queda en el ámbito familiar; Carlo Petrini (2009) afirma que "la alimentación es el acto más político de todos".

Los tres sesgos empujan a los márgenes todo lo que no está dentro de los límites diseñados por el paradigma dominante. Por tanto, para modificar el principio depredador y destructor desarrollista, resulta necesario acercarnos a dichos márgenes, en donde puede realizarse la creatividad, lo que Raúl Zibechi (2011) sostiene como una actividad transformadora que "no puede sino realizarse, por fuera del sistema, en los márgenes del mundo realmente existente". Bajo mi punto de vista esta creatividad se puede encontrar en los lugares de conquista que hemos visto: entre la lucha para el respeto de las diversidades y la recuperación de la memoria biocultural, en la búsqueda de un modelo de sociedad igual y justa, en el respeto por los saberes locales, en el acceso libre a la tierra y a la alimentación; es decir, dentro de las propuestas de nuevos horizontes capaces de transformar la realidad que vienen desde los movimientos sociales “marginales": los indígenas, los ecofeministas y los campesinos.

\section{Hacia la recuperación de las identidades}

Existen muchas leyendas sobre la conquista de América, la mayoría de estas se basan en la idea de que fue algo parecido a un destino inevitable. A menudo no se conocen los eventos, sobre todo porque los conquistadores destruyeron casi todo el material de los nativos, y también porque la idea de la superioridad europea es un elemento que se enseña de forma más leve, incluso a los niños y a las niñas. Se asume con sencillez, por tanto, que es normal que haya ocurrido la conquista, quizás debido a las armas o a la estrategia militar, sin poner en duda la convicción de la posición occidental y olvidando la responsabilidad europea en el peor genocidio que el globo haya visto 
nunca. Las masacres del siglo XX que consiguen atraer la atención de documentales y películas y por los cuales todos nos sentimos afectados en alguna medida, ni siquiera se acercan a la hecatombe de Abya Yala. No es simple estimar el número de muertos, porque los testigos que tenemos resaltan a datos antiguos de escritos como los de Las Casas, que hablan de "millones" de muertos en un sentido de "muchos". En los años ochenta se hablaba de menos de 9 millones de muertos. Hoy, aunque no podemos conocer una cifra precisa, las técnicas actuales han permitido estimar que el número sea alrededor de 70 millones de seres humanos. México antes de la conquista contaba con una población aproximada de 25 millones de personas, reducida a 1 millón en el año 1600 (Todorov, 1992).

Claramente existen razones que van más allá del exterminio voluntario, como la muerte por enfermedad causada por el choque microbiano pero también en este caso debemos interrogarnos. Lo mínimo que se puede hacer es tratar de entender el porqué y el cómo ha pasado este doloroso hecho.

\subsection{La memoria y el tiempo}

Cuando se entra en contacto con el "otro" desconocido, la primera reacción es de alejamiento respecto a los valores del nuevo encuentro y de atribución de los propios valores (Todorov, 1992).

En Europa, durante la mitad del año 1400 había llegado la invención de la imprenta,ç y la escritura ya se usaba desde siglos. Los indígenas tenían un nivel de escritura diferente: de las tres civilizaciones más grandes que encontraron los españoles, los incas no la tenían, los mayas tenían una escritura fonética, los aztecas usaban pictogramas, un factor que fue enjuiciado como negativo desde la perspectiva de los españoles. A su vez, cuando los aztecas tuvieron los primeros contactos con los españoles, les llamaban "extranjeros", "barbudos" o "come anones", en referencia a un fruto que ellos no consumían. Los españoles interpretaron el diferente nivel o la ausencia de escritura como si esta gente fuera atrasada. Lo que no habían entendido era el aspecto cultural fundamental de la memoria: mientras la escritura no podía asumir el rol de soporte a la memoria, este papel recaía en la palabra (Todorov, 1992).

Efectivamente a los aztecas se les reconocía la gran capacidad de oradores; para ellos la palabra mediante el uso del huehuetlatolli representaba una importancia fundamental. 
Los huehuetlatolli eran discursos del pasado que sintetizaban los conocimientos y se recitaban de memoria sin variaciones individuales. Está claro que para los aztecas la referencia al pasado era esencial, de hecho, la educación pública se impartía a todos, ricos y pobres, para que todos conocieran las experiencias y los aportes que los hombres y las mujeres del pasado habían dejado, aprendiendo a vivir el presente. Sin embargo, hay otra característica que se debe conocer, y es que para los mayas y los aztecas la concepción del tiempo es la antítesis respecto a la de los cristianos: el calendario cristiano tiene una cronología en dos dimensiones, una cíclica, que comprende los meses y las semanas, y la otra lineal, es decir que el año no se puede repetir: el tiempo cristiano puede solo avanzar. Todo lo contario a los tiempos maya y azteca que se repiten con una sucesión dentro del mes, del año y del haz de los años. Aunque las secuencias sean iguales, dentro de la secuencia cíclica hay diferencias, pero ninguna se coloca en un tiempo absoluto; esto es difícil de comprender para los occidentales y también para traducir este tipo de cronologías. No es casual que la imagen gráfica del tiempo de los mayas y de los aztecas sea una rueda (o un caracol), mientras la imagen del tiempo occidental es una flecha (es lineal) (Todorov, 1992).

Podemos entender que dado que los tiempos maya y azteca se repiten, el conocimiento del pasado es fundamental, porque pasado, presente y fututo se funden. Como el pasado se repite, el carácter fasto y nefasto de los días, meses y años se establece en la búsqueda de los elementos comunes a los periodos concordantes al pasado. Es posible extraer del pasado informaciones en forma de profecía, por tanto la "profecía es memoria" (Todorov, 1992, p. 104). Por ejemplo, los mayas habían sufrido una invasión por parte de los toltecas, así sabemos que existía una profecía que hablaba de la invasión que está descrita con características parecidas a la invasión española, pero que no era posible definir cuál fuera la descripción de una y cuál de la otra. En realidad el elemento sorpresa fue que el evento era totalmente nuevo y único por venir de tan lejos: los nativos no se esperaban un ataque de un pueblo extraño y por lo tanto del cual no conocían su existencia. Un evento imprevisible y un aspecto cultural confirieron a los españoles la victoria. Muchos cuentos de los "indios" narraban la característica de no ser gente mentirosa. En la cultura azteca se castigaba duramente la mentira, haciendo de los indígenas personas de palabra. Cuando llegaron los cristianos y prometieron querer la paz y la amistad, los aztecas no podían concebir ni comprender esta forma de comunicación manipuladora. Esto, junto al hecho de que incluso la guerra seguía ritos y tradiciones, haciendo que los españoles les conquistaran con no demasiado esfuerzo, reforzando la convicción cristiana por la 
cual el dios cristiano era el único y que todo lo que iba a pasar en el "Nuevo Mundo" no solamente era justificado, sino incluso apoyado por el dios que expresaba una progresión infinita hacia la victoria del espíritu cristiano (Todorov, 1992).

Se encontraron dos culturas, dos modos de hacer la guerra, dos modos de comunicar: mientras los indígenas comunicaban con el cosmos en una expresión de armonía con él, los europeos eran capaces de una comunicación interhumana. Triunfó esta última, y por cierto esta victoria de la cual somos todos hijos e hijas ha provocado una enorme pérdida, creando el espejismo de que todo es una comunicación interhumana, y ha apagado la vocación de comunicarnos con el mundo y sentirnos parte de algo más grande que de un estado-nación (Todorov, 1992). Así, el dominio occidental ha aplastado la capacidad de integración entre ser humano y naturaleza.

La sociedad actual se porta como si solo le importara el presente e imaginando el futuro conectado a la idea de progreso: todo evoluciona y mejora. En realidad necesitamos del pasado, y la memoria tiene exactamente la función de recordarlo. Todo tiene una memoria: los individuos, las sociedades, la entera especie humana (Barrera-Bassols y Toledo, 2008).

\subsection{La memoria biocultural}

La especie humana tiene tres tipos de memoria: la genética, la lingüística y la cognitiva, que cumplen la función de la diversidad de genes, lenguas y conocimientos. Las primeras dos engloban la relación entre humanidad y naturaleza, mientras la tercera se necesita para comprender y evaluar la historia de esta vinculación (Barrera-Bassols y Toledo, 2008).

La historia del ser humano es rica en expansiones geográficas en todos los lugares de la tierra, gracias a la capacidad de la memoria de proveer las informaciones necesarias para enfrentarse a un mundo constituido por un elemento imprescindible, es decir la diversidad. Sin embargo, la modernidad ha cambiado esta realidad evolutiva: el ritmo creciente de una sociedad basada en la acumulación y en la explotación de recursos y riquezas, ha transformado una natural predisposición a la memoria en una tendencia a la amnesia con tratos patológicos, que han hecho que la humanidad olvidara no solamente procesos históricos antiguos, sino los inmediatos. Esta es la consecuencia de la dependencia de las ideas de desarrollo y progreso que pretenden avanzar sin 
ni siquiera mirar atrás, definiendo todo lo que está conectado a la tradición como retrógrado, primitivo e inútil (Barrera-Bassols y Toledo, 2008).

Borrar la memoria de una especie significa no permitirle tener una conciencia que es a la vez conciencia biológica (de la especie) y conciencia histórica, y por tanto no ser capaz de reconocer todas las dimensiones de la realidad de la Tierra, es decir sus diversidades bioculturales (biológicas, cognitivas, lingüísticas, genéticas, agrícolas y paisajísticas).

Sin embargo, hoy en día existen lugares donde se pueden encontrar informaciones para estudiar la memoria biocultural, que está vinculada con las "regiones tradicionales" (Barrera-Bassols y Toledo, 2008, p. 29) del mundo, es decir zonas donde hay una población rural de carácter campesino con un sistema de producción familiar. Los lugares donde se ubica la memoria biocultural son:

1. Los centros de diversidad biológica. O biodiversidad, es decir los lugares con el número de especies presentes en una cierta área y su distribución, que son consecuencia de un proceso evolutivo y de diversificación. Hay tres centros de biodiversidad particularmente ricos de especies en superficies mínimas, que son los que contienen más datos y son: a) los países megabiodiversos, b) las ecoregiones terrestres claves, c) las regiones vírgenes (si es que estas aún existen).

2. Los centros de diversidad lingüística. Los patrones más evidentes en el proceso de diversificación lingüística son cuatro: a) los países lingüísticamente megadiversos, que poseen al menos la mitad de los lenguajes mundiales, b) los países situados en las zonas de alta degradación ambiental, es decir, el trópico húmedo, las áreas semidesérticas, las regiones altas, secas y frías, c) el 0,2 \% de la población mundial que concentra más del 50 \% de la diversidad lingüística, d) ecoregiones lingüísticas donde viven comunidades indígenas.

3. Los centros de agrodiversidad (origen de plantas y animales). Son las áreas donde se ha realizado el proceso de manipulación de los genomas de plantas y animales, creando y domesticando nuevas especies. Estas regiones, clasificadas por el biólogo Nikolaj Vasilov (1926) (Barrera-Bassols y Toledo, 2008, pp. 336-337), son también reconocidas como las zonas de desarrollo de las civilizaciones: China, India, Etiopía, Región Andina, Mesoamérica, Región Mediterránea, Oriente Medio. 
La sabiduría tradicional (e indígena) siempre ha elaborado estrategias de conservación y subsistencia para manejar y mantener la diversidad biológica y cultural, basándose en las necesidades locales que podían comprender incertidumbres de cualquier tipo. En este sentido, cultura y naturaleza aparecen como dos dimensiones que no se pueden separar en cuanto a que construyen el saber local mediante las experiencias individuales y sociales, donde los valores tienen su raíz en el plano de los mitos y de los ritos, produciendo una percepción del mundo sagrada y secular, en la cual se integran completamente con la naturaleza. En esta cosmovisión, la humanidad no está separada de la naturaleza y los seres vivos no-humanos no están separados de la cultura. Se trata de una percepción del mundo natural que es multidimensional, dinámica y polivalente, a diferencia de la imagen de la naturaleza dada por la "ciencia" donde se ve un mundo natural, fijo y estático. Esta ciencia "moderna" se constituye por tres principios:

- El determinismo universal, que afirma que el ser humano posee la habilidad de conocer los eventos del pasado y predecir los eventos del futuro, con el solo aporte de su inteligencia.

- El reduccionismo, que reduce a componentes básicos los elementos de una totalidad para conocerla mediante dichos componentes.

- La disyunción, que fragmenta la realidad para dividirla en diferentes disciplinas y analizarlas separadamente.

Por lo tanto, la ciencia moderna considera los saberes locales como cerrados y etnocéntricos, opuestamente a lo que la ciencia occidental se autodeclara como sistema universal, abierto y progresivo (Barrera-Bassols y Toledo, 2008).

Para explicar la diferencia entre ciencia y sabiduría, es interesante analizar la diferencia entre conocimiento y saber: mientras el conocimiento es una creencia caracterizada por un razonamiento objetivo y "universal", la sabiduría es un razonamiento fundado sobre la experiencia personal y las creencias tradicionales (Barrera-Bassols y Toledo, 2008).

Como hemos visto anteriormente, la mirada occidental denigra lo saberes locales contraponiéndolos a la supuesta universalidad científica, al "conocimiento", pero apropiándose de la diversidad, ocultándola a la vez y haciéndola territorio de conquista. 
Así, la recuperación de la memoria biocultural es fundamental para buscar un nuevo paradigma alternativo. Por esta razón a nivel sociopolítico se necesita un proyecto que tenga en cuenta la pluralidad de la realidad, estamos hablando de la propuesta del horizonte del Buen Vivir.

\subsection{El horizonte del Buen Vivir o de los Buenos Vivires}

Los pueblos indígenas y los campesinos poseen un enlace especial con la tierra y con la naturaleza en general, la cual tiene un rasgo de sacralidad, muy diferente de la visión occidental (Barrera-Bassols y Toledo, 2008; Pérez, 2007).

Esta sensibilidad es la base de muchas movilizaciones de los pueblos originarios (y los otros grupos marginalizados, como mujeres y campesinos) que han surgido en Latinoamérica recientemente, mostrando una propuesta política y social opuesta al proyecto neoliberal de la euromodernidad y poniendo totalmente en discusión los fundamentos del modelo moderno, como el dualismo entre naturaleza y sociedad, la jerarquización de los saberes locales y la prioridad del crecimiento económico: en otras palabras a las concepciones del desarrollismo (Loera, 2015).

Además, si desde un lado estas formas de protesta han dado voz a grupos sociales históricamente marginados, representando un momento de emancipación social, desde el otro, estas transformaciones sociales han fortalecido los movimientos globales ambientalistas y altermundistas. Todo esto ha conllevado una gran visibilidad en todo el mundo al horizonte del Buen Vivir, que se ha hecho motor de la lucha de resistencias contra la globalización económica y ha comenzado a expresar la posibilidad de un cambio de modelo frente a la idea imparable del desarrollo, así que el horizonte del Buen Vivir constituye una propuesta de los movimientos indígenas, pero no solamente para los indígenas (Vanhulst, 2015).

Eduardo Gudynas y Alberto Acosta (2011) afirman que el Buen Vivir es una “oportunidad para construir otra sociedad sustentada en la convivencia del ser humano en diversidad y armonía con la naturaleza, a partir del reconocimiento de los diversos valores culturales existentes en cada país y en el mundo" (citados por Vanhulst, 2015, p. 4). En esta definición es claro que el Buen Vivir es un proyecto en construcción, con la idea de realizar más una plataforma que un concepto preciso y único. Por esta razón, sería más adecuado empezar a hablar de "Buenos Vivires en el espacio de los márgenes como lugar-proceso necesario donde puedan coexistir saberes mediante 
una constante articulación de diferencias ontológicas” (Loera, 2015). El horizonte del Buen Vivir se propone como discurso alternativo al modelo dominante de desarrollo, combinando especialmente tres elementos: 1) los principios de la cultura andina, 2) la contribución crítica de algunos estudiosos contemporáneos, 3) la incorporación de dichos principios a nivel político, incluso en las constituciones (como ha ocurrido en Ecuador y Bolivia). A partir de esta subdivisión se pueden definir algunos tipos de Buenos Vivires que podemos incluir en tres grupos (Vanhulst, 2015):

a. La corriente llamada "indigenista", constituida por la idea de la autodeterminación de los pueblos indígenas. En este grupo el concepto de Buen Vivir viene de la noción quechua Sumak Kawsay y de la aymara suma qamaña, podemos encontrarla también en manera parecida en otras culturas originarias, como el nandereko de los guaranís, el küme mongen de los mapuches y el shiir waras de los achuar. Todos estos convergen en una filosofía que expresa el vivir en equilibrio y en armonía con los ciclos de la pachamama y con cualquier forma de existencia ${ }^{1}$.

b. La segunda es la corriente postestructuralista, que concierne a la esfera más académica. En este campo, la reflexión es estimulada mediante la referencia al Buen Vivir como concepto contra el desarrollo modernista eurocéntrico. La discusión intelectual se centra en los aspectos de "alternativa”, "descolonización”, "utopía”.

c. La última es la corriente socialista, incorporada dentro de la esfera política, protagonista en el tema de la gestión de la política estatal, la equidad social y las cuestiones ambientales.

Desde aquí podemos distinguir cuatro componentes de la plataforma de los Buenos Vivires como elementos fundamentales de los horizontes del Buen Vivir, es decir: 1) la idea de equilibrio e integración con la naturaleza, 2) la reivindicación de los grupos y pueblos marginados y subordinados, 3) el principio de que el Estado tenga que garantizar las necesidades básicas (agua, alimentación, educación, salud), la justicia social y la igualdad, 4) la democracia (Vanhulst, 2015).

Los Buenos Vivires se proponen como horizontes críticos alternativos al paradigma neoliberal (al modelo eurocéntrico, antropocéntrico, capitalista y universalista) y

1 Claramente se debe poner atención para no caer en idealizaciones y mistificaciones de la cultura indigena. 
como proyectos políticos interculturales tratando de empezar un cambio "postneoliberal" (Sader, 2007; Stefanoni, 2012).

Lo que resulta fundamental es que representa un modelo de valorización de las diversas culturas que rompe con la idea de que el conocimiento sea propiedad exclusiva de los expertos, legitimando el conocimiento y sobre todo la sabiduría de las personas que aspiran a la construcción de un mundo más humano y sostenible (De la Cuadra, 2015); del mismo modo, toma distancia de la filosofía cartesiana y reduccionista para sugerir una cosmovisión que involucra un sistema integrado en su conjunto con una perspectiva biocéntrica y una concepción de la cultura como realidad plural (Vanhulst, 2015).

\section{Conclusiones}

A lo largo del trabajo hemos analizado las problemáticas provocadas por el paradigma occidental, es decir, por el pensamiento moderno con sus principales fundamentos para deconstruirlo y proponer un lugar de lucha desde donde empujar la construcción alternativa: los márgenes. Estos aportan elementos importantes donde el resultado de la trama es una realidad plural con una visión pluriversal que intenta instaurar un equilibro entre los seres humanos y los no-humanos.

La sociedad eurocentrada ha impuesto un sistema patriarcal que ha dictado unas normas, previendo estar dentro de algunos límites precisos y describiendo al resto del mundo en relación a lo que no era incluido en el pensamiento dominante. Después de haber declarado la libertad y la igualdad de toda la humanidad, estableció a quién dar el estado de "hombre libre e igualitario", asignando los roles a todo el mundo y afectando todo los ámbitos posibles: las mujeres blancas como reproductoras de la "raza", la gente no-blanca como "animales" para trabajar (Lugones, 2008) la naturaleza para los recursos.

Hoy en día, los movimientos analizados, al criticar duramente dicho sistema, están poniendo sobre la mesa propuestas de cambio y de construcción de nuevos conceptos. Los principios andinos vienen de los indígenas, pero no son aplicables solo a la 
cultura andina, sino a la humanidad, por su sentido de respeto de las diversidades, de igualdades entre los seres vivos y humanos y de justicia social.

\section{Referencias}

Barrera-Bassols, N., Toledo, V. (2008). La memoria biocultural. La importancia ecológica de las sabidurías tradicionales. Barcelona: Icaria.

Bautista, J. J. (2014). ¿Qué significa pensar desde América Latina? Hacia una racionalidad postmoderna y postcolonial. Madrid: Ediciones Akal, S. A.

Carvalho, R., y Friggeri, F. (2015). Heterogeneidad estructural y socialismo del Buen Vivir. Polis, 40. doi: 10.4000/polis.10633.

Corrado, A. (2010). Il paradigma dei semi: Crisi agro-alimentare e reti per unaltra agricoltura. Aracne, Roma.

Costanzo, M. (2014). La dissacrazione del cibo la "ricetta veloce", Lanima del cibo. Massaro, A. (A cura di). Roma: Aracne.

De la Cuadra, F. (2015). Buen Vivir: ¿Una auténtica alternativa postcapitalista? Polis Revista Latinoamericana, 40, 1-11. Recuperado de http://polis.revues.org/10893

Eibl-Eibesfeldt, I. (1993). Biología del comportamiento humano: manual de etología humana. España: Editorial Alianza.

Foucault, M. (2005). Sicurezza, territorio, popolazione. Corso al Collège de France (1977-1978). Milano: Feltrinelli.

Hardt, M., \& Negri, A. (2004). Moltitudine. Guerra e democrazia nel nuovo ordine imperiale. Milano: Rizzoli.

Loera, J. J. (2015). La construcción de los Buenos Vivires; entre los márgenes y tensiones ontólogicas. Polis, 40. doi: 10.4000/polis.10654.

Lugones, M. (2008). Colonialidad y género: hacia un feminismo descolonial, género y descolonialidad. Mignolo, W. (Comp.). Buenos Aires: Ediciones del Signo.

Matera, V. (2006). Antropologia in sette parole chiave. Palermo: Sellerio Editore.

Mead, M. (1967). Sesso e temperamento. Milano: Il Saggiatore. 
Mignolo, W. (2008). Introducción, ¿cuáles son los temas de género y (des)colonialidad?, género y descolonialidad. Argentina: Ediciones del Signo.

Momsen, J. H. (2004). Gender and Development. Trowbridge: Routledge.

Patel, R. (2011). I padroni del cibo. Milano: Feltrinelli.

Pérez-Vitoria, S. (2007). Il ritorno dei contadini. Milano: Jaka Book.

Petrini, C. (2009). Terra Madre. Come non farci mangiare dal cibo. Milano: Giunti.

Quijano, A. (2000). Colonialidad del poder, eurocentrismo y América Latina, la colonialidad del saber: eurocentrismo y ciencias sociales. Lander, E. (Comp.). Perspectivas Latinoamericana, (pp. 246-276). Buenos Aires: CLACSO, Consejo Latinoamericano de Ciencias Sociales.

Ruspini, E. (2006). Identità di gener. Roma: Carocci.

Sader, E. (2007). I colori anti-liberisti della nuova talpa latinoamerica. Alternative per il socialismo, (1). Roma: Editori Riuniti.

Shiva, V. (2006). Il bene comune della terra. Milano: Feltrinelli.

Shiva, V. (2002). Il mondo del cibo sotto brevetto. Controllare le sementi per governare i popoli. Milano: Feltrinelli.

Soler, M., y Pérez, D. (2014). Alimentación, agroecología y feminismo: superando los tres sesgos de la mirada occidental, género, agroecología y soberanía alimentaria. Siliprandi, E., y Zualuaga, G. (Coords). Barcelona: Icaria.

Sousa, B. (2009). Una epistemología del Sur. Cerro del Agua: Siglo Veintiuno.

Stefanoni, P. (2012). Posneoliberalismo cuesta arriba. Los modelos de Venezuela,Bolivia y Ecuador en debate. Nueva Sociedad, (239), 51-64, University Library System of the University of Pittsburgh.

Todorov, T. (1992). La conquista dell'America. Il problema dell' "Altro". Torino: Einaudi.

Tosi, S. (2013). Sociologia, cibo, alimentazione: alcuni appunti, 1-27. Recuperato http:// www.nettuno.unimib.it 
Vanhulst, J. (2015). El laberinto de los discursos del Buen Vivir: entre Sumak Kamsay y socialismo del siglo XXI. Polis, (40). doi: 10.4000/polis.10727.

Vitale, A. M. (2008). I movimenti rurali: biopolitica e ingovernabilità sociologia urbana e rurale. A. XXX, (87), 100-114.

Zibechi, R. (2011). El Buen Vivir como "el otro mundo posible". Revista El Emilio, (6). Recuperado de http://www.revistaelemilio.com.ar 